\title{
Opções contraceptivas e vivências da sexualidade: comparação entre mulheres esterilizadas e não esterilizadas em região metropolitana do Sudeste do Brasil*
}

\section{Contraceptive choices and experiences of sexuality: a comparison between sterilized and non-sterilized women}

\section{Wilza Villela e Regina Barbosa}

Instituto de Saúde da Secretaria de Estado da Saúde de São Paulo. São Paulo, SP - Brasil

\begin{abstract}
Resumo
Foi realizado estudo de corte transversal com 357 mulheres, respectivamente 174 esterilizadas e 183 não esterilizadas, visando a comparar o comportamento sexual e reprodutivo. A elaboração do instrumento de pesquisa foi precedida da realização de grupos focais, com homens e com mulheres, de modo a adequar o vocabulário e definir as categorias de respostas incluídas em cada um dos itens do questionário. Os resultados mostraram que as mulheres esterilizadas - que apresentam uma média etária mais alta e mais freqüentemente têm parceiros fixos - estão mais aderidas aos modelos tradicionais de feminilidade. Nenhuma mulher esterilizada usou o condom nos trinta dias que antecederam à entrevista. O estudo sugere que as propostas de prevenção do HIV, das doenças sexualmente transmissíveis e do câncer cérvico uterino, levem em consideração a questão das mulheres esterilizadas, desenvolvendo estratégias específicas de promoção do uso do condom para esse segmento da população.
\end{abstract}

Conhecimentos, atitudes e práticas. Comportamento sexual. Esterilização tubária.

\begin{abstract}
s
A cross sectional study involving 357 women, 174 of them sterilized and 183 non-sterilized, with a view to comparing their sexual and reproductive behaviour, was undertaken. The questionnaire was based on previous focus group discussions with both women and men, to find out the best way to approach related questions. The results show that sterilized women - who are older and more often have steady partnerships than non-sterilized womenfulfil traditional gender roles more closely than the others. Furthermore, no sterilized woman had used the condom in the month prior to the interview. It is suggested that public messages for the prevention of the spread of the HIV,
\end{abstract}

Correspondência para/Correspondence to: Wilza Villela - Instituto de Saúde da Secretaria de Estado da Saúde de São Paulo. Rua Santo Antonio, 549 - $2^{\circ}$ andar - 01314-000 São Paulo, SP - Brasil.

Edição subvencionada pela FAPESP. Processo 95/2290-6.

Recebido em 26.6.1995. Reapresentado em 9.4.1996. Aprovado em 14.4.1996. 
sexualy-transmissible disease and cervical cancer should target women who have been sterilized for the purpose of increasing the use of the condom in accordance with specific strategies.

Knowledge, attitudes, practice. Sexual behavior. Sterilization, tubal.

\section{INTRODUÇÃO}

Em todo o mundo a prática da esterilização cirúrgica com fins contraceptivos aumentou consideravelmente ao longo dos últimos vinte anos. Segundo Berquó ${ }^{1}$ (1993), este é o método mais usado por mulheres brasileiras acima de vinte anos de idade, embora sua distribuição não seja homogênea entre as regiões do País, ou entre os segmentos sociais de uma mesma região. E apesar de o Programa de Assistência Integral à Saúde da Mulher, de responsabilidade do Ministério da Saúde ter se proposto, a partir de 1983, a garantir o acesso da mulher a todos os meios contraceptivos existentes no mercado, até hoje o perfil de uso da anticoncepção no Brasil aponta o privilegiamento quase exclusivo da pílula e da esterilização.

A falta de informações e acesso às demais alternativas contraceptivas, a precariedade dos serviços de planejamento familiar e ainda uma cultura sexual baseada na desresponsabilização masculina frente à anticoncepção têm sido apontadas como alguns dos determinantes desta situação. Um contexto social peculiar, onde a esterilização é percebida, por algumas mulheres, como status, e um conjunto de pressões pela redução do tamanho das famílias e pela praticidade na contracepção são outros fatores que também interferem no delineamento deste quadro (SOF $\left.{ }^{7}, 1994\right)$.

A alta prevalência da esterilização tem fomentado um vigoroso debate que inclui desde representantes de diversos segmentos da sociedade civil, atuando na perspectiva dos direitos reprodutivos, até os prestadores de serviços, que se colocam como atendendo desejos ou necessidades das mulheres. Ao mesmo tempo, aspectos relacionados à segurança e inocuidade da cirurgia, bem como a possibilidade de arrependimento posterior também são postos em questão.

Mais recentemente, o aumento das DSTs entre as mulheres, e em particular da infecção pelo HIV e a AIDS - que em São Paulo já atinge a cifra de 7.580 casos notificados até outubro de $95^{3}$ - veio agregar a essas uma nova inquietação. O uso do condom, estratégia fundamental para o controle desta epidemia, não goza de grande popularidade no País, estando sua prevalência de uso situada abaixo dos $5 \%$, segundo diferentes estudos. Ao mesmo tempo, pesquisa realizada em Baltimore (USA), em 1992, apontava que $78 \%$ das mulheres esterilizadas nunca usam o condom, em contraposição a $46 \%$ de mulheres não esterilizadas $\left(\mathrm{CDC}^{4}, 1992\right)$. Estudos semelhantes apresentam resultados similares, sugerindo que a esterilização pode ser mais um fator relacionado à vulnerabilidade feminina ao HIV.

Especialmente em países como o Brasil, as razões que levam à escolha da esterilização em grande medida se confundem com aqueles que definem a situação desvantajosa de muitas mulheres, tornando-as mais susceptíveis à infecção pelo HIV: desconhecimento do próprio corpo, dificuldade de acesso a serviços que atendam com qualidade as necessidades de saúde reprodutiva, pouco poder no interior das relações afetivo sexuais e baixa capacidade de negociação na esfera da sexualidade.

Cabe lembrar, ainda, que estudos recentes enfocando a esterilização (Berquó e Arilha² 1993), apontam que a maioria das mulheres a vivencia positivamente, pela despreocupação que esta traz às suas vidas, em que pesem o ônus quando da sua realização ou após. Da mesma forma, diferentes pesquisas sobre o uso de contraceptivos no Brasil confirmam que as mulheres lidam com a contracepção como um encargo a mais nas suas vidas, preferindo usar métodos que impliquem o menor esforço possível, o que se constitui em obstáculo adicional ao uso do condom (Lago e col. ${ }^{6}, 1993$ ).

O presente trabalho apresenta o resultado de um estudo realizado na cidade de São Paulo, visando a comparar o comportamento sexual e reprodutivo entre mulheres esterilizadas e não esterilizadas, na perspectiva de abordar as diferenças de opções contraceptivas em função do modo particular como estas se articulam às experiências sexuais e reprodutivas das mulheres, e às suas vivências e representações do feminino e do ser mulher. 


\section{MATERIAL E MÉTODO}

Um questionário composto de questões fechadas a respeito do comportamento sexual e reprodutivo, destinado a mulheres, foi desenvolvido a partir da realização prévia de sete grupos focais, respectivamente cinco com mulheres, e dois com homens, de diferentes camadas sociais e práticas contraceptivas. A realização dos grupos focais visou adequar códigos de linguagem e apreender representações a respeito de masculinidade/feminilidade, maternidade, sexualidade, doenças sexualmente transmissíveis (DSTs), AIDS e uso de condom - tomados como fatores relacionados à esterilização e à possibilidade de adoção de práticas preventivas durante o intercurso sexual.*

A amostra de mulheres pesquisadas foi extraída de outra que compunha o projeto "Saúde Reprodutiva da Mulher Negra"**. Para composição da amostra do presente projeto foram excluídas as mulheres com menos de 25 anos, pela baixa prevalência da esterilização nesta faixa, e as que declararam, na primeira pesquisa, intenção de se esterilizar, o que resultou num total de 523 mulheres elegíveis. Destas, 414 foram entrevistadas em seus domicílios, e 109 não foram localizadas. Houve a exclusão, após a entrevista, de 57 mulheres, que tinham parceiros vasetomizados, estavam histerectomizadas ou não tinham atividade sexual. Para efeito de análise, portanto, foram incluídas 357 mulheres, 174 esterilizadas e 183 não esterilizadas (Tabelas 1 e 3 ).

Tabela 1 - Número de mulheres incluídas na amostra segundo faixa etária e opção pela esterilização.

\begin{tabular}{cccc}
\hline Faixa etária & Esterilizada & Não esterilizadas & Total \\
\hline $25-34$ & 77 & 138 & 215 \\
$35-50$ & 155 & 153 & 308 \\
\hline Total & 232 & 291 & 523 \\
\hline
\end{tabular}

Tabela 2 - Distribuição das variáveis de estratificação das mulheres entrevistadas em relação ao total da amostra.

\begin{tabular}{lc}
\hline Variáveis de estratificação & $\%$ de mulheres entrevistadas \\
\hline Idade & \\
$25-34$ & $76,3 \%$ \\
$35-50$ & $81,2 \%$ \\
Raça & $75,0 \%$ \\
Negra & $82,8 \%$ \\
Branca & \\
Nível de escolaridade & $78,4 \%$ \\
1- 4 anos de estudo & $77,0 \%$ \\
$5-8$ anos de estudo & $81,8 \%$ \\
mais de 8 anos de estudo & \\
Bairro de moradia & $77,2 \%$ \\
Butantã & $81,8 \%$ \\
Vila Brasilândia & $78,4 \%$ \\
Ipiranga & \\
Situação reprodutiva & $79,8 \%$ \\
Esterilizada & $78,7 \%$ \\
Não esterilizadas & \\
\hline
\end{tabular}

Tabela 3 - Número e proporção de mulheres incluídas e excluídas da análise segundo razões de exclusão.

\begin{tabular}{lrr}
\hline Razão de exclusão & $\mathrm{N}$ & $\%$ \\
\hline Mulheres incluídas & 357 & 86,3 \\
Mulheres excluídas & & \\
. Não iniciaram vida sexual & 12 & 2,9 \\
. Histerectomizadas & 18 & 4,3 \\
. Parceiro vasectomizado & 27 & 6,6 \\
\hline Total & 414 & 100,0 \\
\hline
\end{tabular}

As 109 mulheres não entrevistadas, em função de mudança de endereço, não localização do endereço ou da mulher no endereço, ou recusa, não apresentam diferenças estatisticamente significativas em relação à amostra, no que se refere à idade, local de moradia, situação contraceptiva (esterilizada ou não) e escolaridade (Tabela 2), varáveis de estratificação do estudo. Assim, as perdas não introduziram vieses nos resultados.

\section{Plano de Análise}

A comparação dos aspectos econômicos, sociodemográficos e de vida reprodutiva entre mulheres esterilizadas e não esterilizadas foi feita por análise bivariada. Valores e opiniões referentes à maternidade, ao uso do condom, aos papéis feminino e masculino, sexualidade e negociação sexual foram analisadas através do uso de escalas. Para aprofundar a compreensão do uso do condom foi usada a regressão logística. A análise foi realizada com a aplicação do software SPSS for Windows.

O material dos grupos focais foi analisado em separado, pelo método de análise de discurso, visando não apenas subsidiar a elaboração do questionário, como também aprofundar a compreensão dos resultados da etapa quantitativa, buscando compreender os diferentes atributos através dos quais as culturas e subculturas demarcam as diferenças entre o masculino e o feminino (Heilborn ${ }^{5}$, 1994). $* * *$

\section{RESULTADOS}

\section{Características Sociodemográficas da Amostra}

Os grupos de mulheres esterilizadas e não esterilizadas são semelhantes em termos de raça, nível de consumo e trabalho fora de casa. Entretanto, a escolaridade média das mulheres não esterilizadas é maior que a das esterilizadas, em particular quando se consideram os níveis educacionais mais baixos e os mais elevados. Além disso, as mulheres esterilizadas estão concentradas na faixa etária superior e têm, em

\footnotetext{
* Os grupos com mulheres incluíram participantes entre 25-40 anos, com nível de escolaridade homogêneo em cada grupo. Assim, foram realizados dois com mulheres de nível universitário, um com mulheres de escolaridade intermediária e dois com mulheres de escolaridade elementar. Nestes últimos, um contou apenas com mulheres esterilizadas. Os grupos masculinos foram compostos por homens de escolaridade média, nos mesmos limites etários que os grupos femininos. Em todos os grupos a maioria dos participantes exercia alguma atividade remunerada fora de casa.

** Projeto desenvolvido pelo Centro Brasileiro de Análise e Planejamento (CEBRAP), coordenado pela Prodessora Elza Berquó.

*** Os resultados detalhados desta análise estão apresentados em Villela e Barbosa ${ }^{8}$.
} 
média, número maior de filhos. Entre as mulheres não esterilizadas encontra-se uma maior proporção de mulheres sem parceiro fixo. Assim, pode-se caracterizar genericamente as mulheres esterilizadas como sendo mais velhas, com mais filhos e, predominantemente, envolvidas em parcerias fixas.

\section{Vida Reprodutiva}

Embora 72,4\% das mulheres esterilizadas tenham três ou mais filhos, chama atenção a percentagem de mulheres esterilizadas com um ou dois filhos $(26,4 \%)$, e mesmo sem nenhum filho vivo. Existe tendência a gestações em idades menores nas mulheres esterilizadas que não reflete uma diferença na idade de início da vida sexual. Apesar de não haver diferença na média dos dois grupos, as mulheres esterilizadas referem uma proporção maior de gestações durante o uso de métodos contraceptivos, o que permite pensar que as mulheres que buscam esterilização de alguma forma experimentaram maior grau de tensão nas suas vidas reprodutivas. Além disso, o perfil sociodemográfico dessas mulheres (faixa etária, escolaridade) sugere um leque mais limitado de recursos pessoais e no seu meio social para o manejo das suas questões reprodutivas, colocando a esterilização como uma estratégia aparentemente mais fácil e segura para a viabilização de uma vida sexual sem a decorrência imediata da gravidez.

Não há diferença entre os dois grupos no que se refere a uso de contracepção na primeira relação sexual, ou no total de métodos utilizados ao longo da vida. No momento da entrevista, $44 \%$ das mulheres não esterilizadas não usavam contraceptivos e $28,2 \%$ usavam pílulas.

\section{Vivência da Esterilização}

Pouco mais da metade das mulheres esterilizadas $(58 \%)$ refere como razão básica para a cirurgia o fato de não quererem mais filhos. Como pondera Berquó ${ }^{1}$ (1993), este é um indicador importante da mudança da mulher em relação aos direitos reprodutivos, na medida em que afirma um desejo próprio e não uma necessidade médica ou socialmente definida, como aparece em estudos anteriores sobre o tema. Embora a maioria das mulheres afirme não ter sentido alterações de saúde após a esterilização, 21,4\% falam de repercussões positivas, enquanto $30,5 \%$ apontam consequiências negativas, como alterações menstruais, mudanças psicológicas ou variações no peso corporal. Quanto à sexualidade, cerca de metade das mulheres referem algum impacto, quer seja o aumento ou diminuição do desejo próprio, ou do parceiro. Quase um quinto das mulheres relata maior dificuldade em recusar-se ao parceiro após a cirurgia, e $27 \%$ dizem que este ficou mais ciumento.

Em que pesem os problemas apontados, $86,7 \%$ referem estar satisfeita com a cirurgia, independente de ter ou não parceiro fixo, sugerindo que reduzir a tensão produzida pelo medo de engravidar é compensatório aos efeitos adversos da cirurgia.

A percepção dos homens sobre os possíveis efeitos da laqueadura, obtida nos grupos focais, é contraditória. Alguns referem a "voz corrente"de que a esterilização estraga a mulher, embora esta não seja sua experiência pessoal, ou a dos seus amigos. Outros são mais radicais, afirmando que "se os homens tivessem consciência, as mulheres não precisariam se esterilizar"...

\section{Conjugalidade}

Observa-se entre as mulheres esterilizadas um tempo maior de relações conjugais, o que pode ser um efeito da sua idade média ser também mais alta. Entretanto, cerca da metade das mulheres esterilizadas refere ter tido um único parceiro sexual ao longo da vida, o que sugere uma tendência à monogamia que se confirma quando é considerado o número de parceiros no último ano, diferente estatisticamente do das mulheres não esterilizadas.

Apesar das diferenças entre tempo de relação conjugal e número de parceiros no último ano, entre mulheres esterilizadas e não esterilizadas, sua percepção das relações é semelhante: apenas 59,6\% das mulheres que têm parceiros fixos acreditam estar numa relação mutuamente monogâmica. Cabe ressaltar que 94,4\% das mulheres afirmam ser monogâmica, de modo que a diferença entre o seu comportamento e a percepção da sua realidade conjugal está relacionada à possibilidade, admitida pelas entrevistadas, de relações extraconjugais por parte do parceiro (Tabela 4).

O material colhido nos grupos focais permite que se entenda melhor esta perspectiva da mulher em

Tabela 4 - Percentual de mulheres esterilizadas e não esterilizadas segundo o número de parceiros sexuais e tipo de relação .

\begin{tabular}{lcc}
\hline Características & \% esterilizadas \% não esterilizadas \\
\hline $\begin{array}{l}\text { Mais de um parceiro } \\
\text { no último ano }\end{array}$ & 1,7 & $4,4^{*}$ \\
$\begin{array}{l}\text { Mais de um parceiro } \\
\text { na vida }\end{array}$ & 31,2 & $47,5^{* *}$ \\
Monogamia feminina & 96,2 & 92,5 \\
Monogamia mútua & 59,6 & 59,7 \\
$*$ p $=0,14$ & & \\
$* * \mathrm{p}<0,05$ & &
\end{tabular}


relação à fidelidade do parceiro. De fato, tanto na concepção feminina quanto na masculina, o desejo do homem é incontrolável, irracional. O homem, por sua "natureza", responderia a qualquer estímulo de ordem sexual, o que potencialmente o levaria a ter relacionamentos extraconjugais, independente do seu amor, real ou virtual, pela companheira. Sabedora disto, a mulher evita conversar a respeito de fidelidade com o parceiro, ao mesmo tempo em que admite não ser capaz de garantir a fidelidade dele.

\section{Reprodução, Sexualidade e Visões do Masculino e do Feminino}

Numa diferença significativa em relação às mulheres não esterilizadas, as esterilizadas consideram que evitar gravidez é uma tarefa feminina. A exigência do casamento para que possa haver uma relação sexual e a perspectiva de que a iniciativa erótica deve ser masculina também são posturas mais freqüentes entre as mulheres esterilizadas (Tabelas 5, 6, 7). Embora este achado possa sugerir maior adesão aos estereótipos femininos tradicionais entre as mulheres esterilizadas, é sensato não admitir, precipitadamente, uma relação de causalidade, e sim considerar esterilização e aderência a estereótipos do feminino como componentes de um perfil de atributos de um determinado grupo de mulheres.
Ao mesmo tempo, a percepção de algumas mulheres de que a contracepção é uma de suas tarefas está relacionada à idéia, tanto feminina quanto masculina, de que as mulheres são mais responsáveis, o que confere uma conotação positiva ao fato de a mulher arcar sozinha com as consequiências de um ato a dois, segundo depoimentos colhidos nos grupos focais. É também em torno de idéias sobre as características da sexualidade de homens e de mulheres que se organiza o padrão da iniciativa sexual predominantemente masculina. De fato, se para os homens o sexo é uma necessidade ancorada na sua biologia (ou "natureza"), para as mulheres o sexo estaria subordinado à vontade, embora esta deva ser despertada pelo desejo masculino. Assim, mesmo entre as mulheres que afirmaram não ter preferência entre procurar e ser procurada, a situação mais freqüente foi a de que a relação sexual fosse buscada pelo parceiro.

\section{As Práticas Sexuais}

Em termos de repertório sexual, a penetração vaginal é a prática mais comum, seguida pela masturbação mútua e o sexo oral. O coito anal aparece como a prática sexual menos popular; embora algumas mulheres o tenham experimentado, esta modalidade de sexo não é incorporada ao seu cotidiano (Tabela 8).

Tabela 5 - Percentual de mulheres esterilizadas e não esterilizadas segundo atributos de masculinidade e de feminilidade.

\begin{tabular}{lcc}
\hline Atributos & \% esterilizada & \% não esterilizada \\
\hline Evitar filhos é uma tarefa essencialmente da mulher & 64,4 & $53,2 *$ \\
Cuidar dos filhos é uma tarefa essencialmente da mulher & 59,2 & 51,9 \\
Homens já nascem com pouca habilidade para cuidar de crianças & 74,7 & 64,5 \\
Mulheres já nascem com o dom de cuidar de casa & 69,0 & 66,7 \\
\hline
\end{tabular}
$* \mathrm{p}<0,05$

Tabela 6 - Percentual de mulheres esterilizadas e não esterilizadas segundo papéis sexuais masculino e feminino.

\begin{tabular}{lcc}
\hline Papéis sexuais & \% esterilizadas & \% não esterilizadas \\
\hline Preferem que o homem inicie a relação sexual & 85,2 & $76,4^{*}$ \\
A relação sexual é iniciada pelas mulheres & 17,4 & 20,0 \\
É o homem quem deve tomar a iniciativa do namoro & 59,2 & $47,2 *$ \\
\hline
\end{tabular}
$* \mathrm{p}=0,05$

Tabela 7 - Percentual de mulheres esterilizadas e não esterilizadas segundo significados conferidos à sexualidade.

\begin{tabular}{|c|c|c|}
\hline Significado da sexualidade & $\%$ esterilizadas & \% não esterilizadas \\
\hline Ter relação sexual é importante para os dois, mas o homem tem mais necessidade & 70,7 & 76,5 \\
\hline O sexo é mais importante para o homem do que para a mulher & 32,2 & 34,4 \\
\hline Para acontecer uma relação sexual tem que estar casado & 36,8 & 21,9 \\
\hline Para acontecer uma relação sexual tem que haver amor & 93,1 & 92,9 \\
\hline Sexo serve para manter o relacionamento amoroso & 89,1 & 88,0 \\
\hline Sexo serve para ter prazer & 47,7 & 44,8 \\
\hline Sexo serve para ter filhos & 7,5 & 9,3 \\
\hline
\end{tabular}


Tabela 8 - Percentual de mulheres esterilizadas e não esterilizadas segundo práticas sexuais.

\begin{tabular}{lccccc}
\hline & \multicolumn{2}{c}{ Na vida } & \multicolumn{2}{c}{ Último ano } & \multicolumn{1}{c}{ Última semana } \\
& Esterilizada & Não esterilizada & Esterilizada & Não esterilizada & Total da amostra \\
\hline Penetração vaginal & 100,0 & 100,0 & 92,5 & 87,4 & 63,2 \\
Masturbação mútua & 50,6 & 54,6 & 42,5 & 51,3 & 12,3 \\
Sexo oral homem/mulher & 37,6 & 41,8 & 32,5 & 42,1 & 9,2 \\
Sexo oral mulher/homem & 30,1 & 36,3 & 21,9 & 35,8 & 6,4 \\
Sexo anal & 23,0 & 18,0 & 8,1 & 9,4 & 0,8 \\
\hline
\end{tabular}

A percepção do coito anal não é a mesma para mulheres e homens. Para estes últimos, por exemplo, segundo as falas nos grupos focais, as mulheres gostam de praticá-lo, mas em geral sentem-se tímidas para solicitar ao parceiro, pelas restrições morais que costumam cercar esta prática. Contrárias a esta opinião, as mulheres afirmam não gostar de praticar o coito anal, embora admitam que este é um importante instrumento de barganha na negociação sexual: ceder algumas vezes pode ser "prova de amor" ou "presente de aniversário". Não ceder nunca pode implicar na impossibilidade de recusar qualquer outra demanda erótica por parte do parceiro.

A discordância que aparece a respeito do coito anal também se apresenta se comparado com o que é feito, em termos sexuais, e o valor atribuído a cada uma das práticas em termos do prazer. Com exceção da penetração vaginal, considerada igualmente prazerosa para ambos os sexos, as demais possibilidades sexuais são apontadas pelas mulheres como potencialmente mais prazerosas para os homens do que para elas próprias. E o que elas consideram prazeroso para si nem sempre é o que é realizado, o que também acontece em relação aos homens, embora em menor proporção. Não existem diferenças entre as mulheres esterilizadas e não esterilizadas em relação a estes aspectos (Tabela 9).
Nos dois grupos de mulheres existe a perspectiva de que o sexo, embora importante para homens e mulheres, é mais necessário para os primeiros, sendo também um elemento fundamental na manutenção da relação amorosa. Durante os grupos focais os homens corroboraram esta opinião.

Menos de $10 \%$ das mulheres afirmaram que o sexo servia basicamente à reprodução, o que sugere um estatuto ambíguo no exercício feminino da sexualidade: as mulheres devem satisfazer os homens, que têm necessidade de sexo. Ao mesmo tempo, o sexo também seria para o seu prazer, embora nem sempre isto ocorra de fato. Além disso, embora haja o reconhecimento da importância do sexo para ambos, a mulher deve arcar sozinha com o ônus da contracepção, como se tivesse que pagar um preço pelo seu direito ao prazer.

\section{Negociação Sexual}

As mulheres entrevistadas referiram dificuldades em dizer não quando o parceiro deseja sexo, e mais da metade prefere ter relação mesmo sem vontade, ou mesmo arranjar uma desculpa, de modo a evitar brigas (Tabela 10). O material colhido nos grupos focais sugere haver um certo acordo implícito entre os casais que indica para o homem o significado da

Tabela 9 - Percentagem de coerência entre a prática sexual realizada e considerada agradável para as mulheres e para os homens.

\begin{tabular}{lcc}
\hline Prática sexual & $\begin{array}{c}\text { \% de coerência entre o praticado e o } \\
\text { considerado agradável para a mulher }\end{array}$ & $\begin{array}{c}\text { \% de coerência entre o praticado e o } \\
\text { considerado agradável para o homem }\end{array}$ \\
\hline Penetração vaginal & 97,1 & 98,3 \\
Sexo oral homem/mulher & 80,9 & $92,9 *$ \\
Sexo oral mulher/homem & 66,2 & $92,4^{*}$ \\
Sexo anal & 13,7 & $87,7^{*}$ \\
\hline
\end{tabular}

$* \mathrm{p}<0,05$

Tabela 10 - Percentual de mulheres esterilizadas e não esterilizadas segundo variáveis relacionadas à negociação sexual.

\begin{tabular}{lcc}
\hline Variáveis & \% esterilizadas & \% não esterilizadas \\
\hline É difícil dizer não para o parceiro & 64,4 & 60,1 \\
Mesmo sem vontade, é melhor ter relação para evitar briga & 54,6 & 50,3 \\
É melhor arranjar uma desculpa que dizer não & 54,6 & 54,6 \\
Dizer não é briga na certa & 49,4 & 45,9 \\
\hline
\end{tabular}


desculpa, ao mesmo tempo que reafirma o afeto da mulher, preocupada em não feri-lo com uma recusa. No entanto os homens são enfáticos em afirmar que o uso deste tipo de subterfúgio pelas mulheres não pode ser muito freqüente, sob pena de levantar suspeitas de infidelidade ou desamor. Cúmplices do mesmo acordo implícito, as mulheres reconhecem que não dá para ter muitas relações sem vontade, tanto quanto não dá para sempre usar desculpas, de modo que o ideal é uma mescla de estratégias, incluindo também a de fingir que está gostando "para o marido ficar feliz e terminar rápido". A eventual fertilidade é também uma estratégia para a mulher se escusar de ter relações, e o fato de a mulher esterilizada não poder usá-la reduz seu poder de negociação nesta esfera. Em contrapartida, não se sentir em risco de gravidez é um fator determinante da melhora na qualidade da vida sexual de algumas mulheres.

Tantos esquemas para evitar a relação não significa que as mulheres não gostem de sexo. Apenas a sexualidade não está "na sua natureza", e, portanto, precisa ser despertada, o que envolve um certo esforço. E tanto homens como as mulheres atribuem à sobrecarga de trabalho a que a mulher é submetida, dentro e fora de casa, a sua menor disposição para o sexo.

\section{Conhecimento e Uso do Condom}

O condom é amplamente conhecido nas suas finalidades de prevenção de gravidez e das DSTs/ AIDS. Sua aceitação, no entanto, é pequena, havendo referências a percepções negativas quanto à sua segurança e conotação moral por parte de mais da metade das mulheres.

A interferência no prazer, principal problema apontado pelos homens em relação ao condom, também foi referida por várias mulheres, embora com uma importância menor do que outros atributos negativos relacionados ao método.

A análise multivariada mostra que a percepção positiva do condom está associada ao seu uso, havendo, nestes casos, referência à higiene como a sua maior vantagem.

$\mathrm{O}$ uso anterior do condom foi menor entre mulheres esterilizadas $(44,5 \%)$. Para o conjunto de mulheres que já o experimentou, a finalidade foi, predominantemente, a contracepção, embora as mulheres não esterilizadas, com maior freqüência que as demais, tenham associado a esta também a finalidade de prevenção das DSTs/AIDS. Esta diferença das finalidades atribuídas ao condom pode ser parcialmente explicada pelo fato de as mulheres não esterilizadas serem mais jovens, mais escolarizadas e com menor frequiência de parcerias fixas, o que lhes confere a maior possibilidade de se perceberem em risco e incorporarem medidas de prevenção.

Considerando o mês que precedeu à entrevista, nenhuma mulher esterilizada fez uso do condom.

\section{Informações sobre HIV}

A AIDS não é desconhecida das mulheres entrevistadas, que dispõem de informações básicas a seu respeito, embora cerca de $30 \%$ tomem como verdadeiras as possibilidades de transmissão da infecção por picada de insetos ou de identificação de um portador do vírus por sua magreza.

Quase um terço das entrevistadas conhece alguém que tem ou teve AIDS, e $15 \%$ têm um amigo ou familiar soropositivo; $13,4 \%$ das mulheres declararam ter feito o teste, estando este fato correlacionado com o de conhecer alguém com HIV/AIDS.

Nenhuma das mulheres pesquisadas declarou-se portadora do vírus.

\section{DISCUSSÃO}

A incorporação de dados qualitativos aos resultados de um estudo quantitativo possibilitou uma compreensão mais apurada das respostas obtidas, fundamental para o objetivo do presente trabalho, de relacionar os comportamentos das mulheres com as suas concepções de feminilidade.

Com esse procedimento, reforça o pressuposto de que parte das decisões reprodutivas das mulheres são intermediadas pelas suas representações de si mesmas, e que estas são atravessadas pelo discurso masculino sobre "A Mulher", o que se mostrou útil na interpretação dos presentes achados.

A população estudada - mulheres urbanas adultas - vive um momento de profundas mudanças nos padrões sociais e reprodutivos que repercutem nas relações entre homens e mulheres e nos seus processos de tomada de decisão.

Eficácia e praticidade, por exemplo, passam a ser os atributos mais importantes para a mulher no momento da sua escolha contraceptiva, fazendo com que potenciais efeitos colaterais ou agravos à saúde não sejam valorizados.

Esta perspectiva também é válida para a esterilização. Embora não se tenha tido como objetivo conhecer os determinantes da sua escolha, ou a percepção e vivência das mulheres relacionadas a este procedimento, observa-se que a perspectiva de o trajeto de levar uma mulher a se esterilizar é construído através de diferentes pressões estruturais e conjun- 
turais $\left(\mathrm{SOF}^{7}, 1994\right)$ e não reflete a experiência da mulher. Do ponto de vista individual as mulheres não vivenciam a esterilização como uma contingência, e atribuem a esta opção mais qualidades positivas que negativas. Dado não contarem com a participação dos seus parceiros na contracepção, as mulheres sentem-se aliviadas por poderem eliminar este encargo das suas vidas. O desejo de não terem que se preocupar com medidas preventivas na esfera da sexualidade, no entanto, pode ser importante obstáculo para a prevenção do HIV/AIDS entre mulheres esterilizadas.

Sabe-se que o não-uso do condom durante uma relação sexual aumenta a possibilidade de ocorrência de DSTs, incluindo a infecção pelo HIV. Assim, o fato de nenhuma mulher esterilizada ter usado o condom nos trinta dias anteriores à entrevista é preocupante. Além disso, sua tendência a uma atitude sexual mais passiva - expressa pela preferência da iniciativa masculina, pelo repertório sexual menos diversificado, pela maior aderência a posturas tradicionais, pelas dificuldades de negociação sexual e ainda pelo ciúme do marido - leva a supor que as mulheres esterilizadas teriam dificuldades específicas na incorporação de práticas sexuais preventivas do HIV/AIDS.

A esterilização cirúrgica é mais freqüente entre mulheres casadas e com níveis de escolaridade mais

\section{REFERÊNCIAS BIBLIOGRÁFICAS}

1. BERQUÓ, E. Brasil, um caso exemplar: anticoncepção e parto cirúrgico; a espera de uma ação exemplar. In: Seminário a Situação da Mulher e o Desenvolvimento, São Paulo, 1993. Ministério das Relações Exteriores/NEPO/ UNICAMP.

2. BERQUÓ, E. \& ARILHA, M. Esterilização, sintoma social: relatório de pesquisa. São Paulo, NEPO/ECOS, 1993.

3. BOLETIM EPIDEMIOLÓGICO. Programa DST/AIDS da Secretaria do Estado da Saúde de São Paulo, out/dez, 1995.

4. CENTERS FOR DISEASE CONTROL (CDC). HIV risk behaviors of sterilised and non sterilised women in drug treatment programs. Philadelphia, 1989-1991. MMWR, 41: 149-52, 1992a. baixos, perfil que coincide com uma das faixas da população mais atingidas pelo HIV na cidade de São Paulo ${ }^{3}$, 1995. Assim, as mulheres que optam pela esterilização são, em parte, as mesmas que se apresentam maior vulnerabilidade ao HIV, por razões semelhantes: falta de uma política adequada de oferta de serviços na área da saúde reprodutiva e dificuldade em compartilhar com o parceiro a contracepção.

É importante que os serviços de saúde ofereçam às mulheres que desejam se esterilizar um cuidadoso aconselhamento, no sentido de esclarecêlas sobre a necessidade de continuarem usando uma proteção contra as DSTs/HIV mesmo após a cirurgia, particularmente se a mulher admite a possibilidade de relações extraconjugais por parte do parceiro.

Do mesmo modo, os programas de planejamento familiar devem promover o uso de métodos de barreira, especialmente o condom, incorporando, junto das ações voltadas para a prevenção da gravidez, um amplo conjunto de atividades relacionado à prevenção das DSTs/AIDS, tanto quanto os programas de prevenção do câncer cérvico uterino e do HIV devem considerar a questão das mulheres esterilizadas, desenvolvendo estratégias específicas de promoção do uso do condom junto a essa população.

5. HEILBORN, M.L. De que gênero estamos falando? Sexual. Gênero e Soc., 1 (2), 1994.

6. LAGO, T. Aceitabilidade e efetividade do diafragma entre mulheres brasileiras de baixa renda: relatório de pesquisa. São Paulo, Instituto de Saúde, 1993.

7. SEMPRE VIVA ORGANIZAÇÃO FEMINISTA. Esterilização, caminhos e descaminhos. São Paulo, 1994.

8. VILLELA, W. \& BARBOSA, R. Comportamento sexual e reprodutivo entre mulheres na cidade de São Paulo: repensando as relações entre gênero e sexualidade. In: Parker, R. \& Barbosa, R., org. Sexualidades brasileiras . Rio de Janeiro, ABIA/IMS, 1996. (no prelo) 